\title{
Overview of tympanoplasty techniques and results
}

\author{
Reshma P. Chavan ${ }^{1}$, Shivraj M. Ingole ${ }^{2}$, Santosh N. Birajdar ${ }^{1}$
}

\author{
${ }^{1}$ Department of ENT, Dr. V. M. G. Medical College, Solapur, Maharashtra, India \\ ${ }^{2}$ Department of Radiology, G. G. M. C and Sir J. J group of Hospitals, Mumbai, Maharashtra, India
}

Received: 03 January 2017

Revised: 10 January 2017

Accepted: 18 January 2017

\section{*Correspondence:}

Dr. Reshma P. Chavan,

E-mail: entproblem@gmail.com

Copyright: ( $)$ the author(s), publisher and licensee Medip Academy. This is an open-access article distributed under the terms of the Creative Commons Attribution Non-Commercial License, which permits unrestricted non-commercial use, distribution, and reproduction in any medium, provided the original work is properly cited.

\begin{abstract}
The objective of this article is to overview about the changing techniques of tympanoplasty surgery and increase in the anatomical and functional success rate of surgeries. Introduction of endoscope in ear surgeries is time saving. Endoscopes are helpful to access hidden areas which was difficult with the help of microscope such as facial recesses, sinus tympani, extension of posterior-superior retraction pockets, etc. Also various modifications done in the techniques of using graft material for tympanoplasty surgery are reviewed in terms of graft acceptance and improvement of hearing. Articles reviewed are research articles, original articles and review articles published in pub med indexed journals. Because of newer techniques in ear surgeries, tympanoplasty is becoming day care surgery. Also newer techniques are with cosmetic view and gives maximum post-operative hearing using minimal instrumentation. Efforts are taken to review the tympanoplasty surgical technique and its results.
\end{abstract}

Keywords: Endoscopes, Tympanoplasty, Technique

\section{INTRODUCTION}

Perforation of tympanic membrane is sequelae of chronic supportive otitis media, trauma, etc. Tympanoplasty surgery is done to seal tympanic membrane and to improve hearing. Berthold had done first tympanoplasty in 1878 by applying plaster on de-epithelialized the tympanic membrane remnants for 3 days and removal of plaster applying skin graft over the defect. ${ }^{1}$ Various surgeons have used different kinds of grafts to repair tympanic membrane perforations. Most popular are auto grafts. Zollner (1954) and Frenckner (1955) used pedicled ear canal skin graft to close perforations. ${ }^{2}$ Shea (1960) introduced vein graft to close tympan ic membrane perforations. ${ }^{3}$ Heermann (1960) was first used temporalis fascia as a grafting material in the tympanoplasty. ${ }^{4}$ Spilt thickness and full thickness skin graft were being used previously. Because of graft eczema, desquamation, and poor results skin graft had not become popular among surgeons. Other graft material used to seal tympanic membrane perforation is vein graft, temporalis facia graft, facia lata, tragal cartilage, conchal cartilage etc. Moore GF, et al has used fosse triangularis cartilage and functional outcome was measured by tympanometry. This study shows that fosse triangularis cartilage gives $100 \%$ success rate. ${ }^{5}$ Zahnert et al, had shown same audiological outcome for tragal and conchal cartilage graft for tympanic membrane reconstruction. ${ }^{6}$ Kazikdas et al had shown maximum functional outcome when size of cartilage is reduced to thickness of 500 micrometer. $^{7}$ Yegin et al had shown that functional results with cartilage were independent of thickness of cartilage. ${ }^{8}$ Cavaliere had shown that acoustic properties of cartilage are same as that of fascia. ${ }^{9}$ Depending on size and site of perforation various approaches are used such as endaural, endomeatal and postaural. Microscope allows better instrumentation in bleeding circumstances. It gives magnification to operating field. Marchioni et al had operated on patients having non self-cleansing attic retraction pockets with endoscope. ${ }^{10}$ So the endoscope was first introduced for retraction pocket surgeries and for the disease limited to attic region. Use of endoscope 
in the tympanoplasty is gaining popularity among surgeons. Aim of this article is to review outcome of tympanoplasty, different techniques and graft materials used for tympanoplasty.

\section{SURGICAL TECHNIQUES AND RESULTS}

Various techniques are developed over period of time to give maximal anatomical and functional outcomes. Also long term follow up is required for tympanoplasty patients as there are chances of reperforation over period of time. Possibility of reperforation increases with increase in size of perforation. ${ }^{11}$ Short follow up studies are showing higher success rate than long term follow up studies. ${ }^{12}$ Studies were done to compare success rate of temporal muscle fascia grafts and cartilage grafts in tympanoplasty.

Table 1: Comparison of results of temporal muscle fascia and cartilage grafts.

\begin{tabular}{|c|c|c|c|c|c|}
\hline Study (year) & $\begin{array}{l}\text { Study } \\
\text { population }\end{array}$ & Graft & $\begin{array}{l}\text { Surgical } \\
\text { technique }\end{array}$ & Graft acceptance & $\begin{array}{l}\text { Hearing } \\
\text { improvement }\end{array}$ \\
\hline \multirow{2}{*}{$\begin{array}{l}\text { Yegin et al } \\
(2016)^{8}\end{array}$} & \multirow{2}{*}{78} & Tragal Cartilage & \multirow{2}{*}{$\begin{array}{l}\text { Overlay underlay } \\
\text { technique }\end{array}$} & $92.1 \%$ & $26.11 \pm 12.87 \mathrm{~dB}$ \\
\hline & & Temporalis fascia & & $65 \%$ & $24.25 \pm 12.68 \mathrm{~dB}$ \\
\hline \multirow{3}{*}{$\begin{array}{l}\text { Shishegar et al } \\
(2012)^{13}\end{array}$} & 27 & $\begin{array}{l}\text { Palisade cartilage } \\
\text { Temporalis fascia }\end{array}$ & Underlay-overlay & $100 \%$ & $\begin{array}{l}\text { Same as Palisade } \\
\text { cartilage }\end{array}$ \\
\hline & 27 & & underlay & \multicolumn{2}{|l|}{$92.5 \%$} \\
\hline & $\begin{array}{l}\text { Review } 14 \\
\text { articles } \\
>50 \text { each }\end{array}$ & $\begin{array}{l}\text { Temporalis fascia } \\
\text { verses cartilage } \\
\text { graft }\end{array}$ & Review article & $\begin{array}{l}\text { Level } 1 \text {, level } 3 \text {, } \\
\text { level } 4 \text { evidence to } \\
\text { show better result } \\
\text { with cartilage }\end{array}$ & $\begin{array}{l}\text { Same as cartilage } \\
\text { and Temporalis } \\
\text { fascia }\end{array}$ \\
\hline $\begin{array}{l}\text { Onal et al } \\
(2011)^{15}\end{array}$ & 44 & cartilage & - & $93.2 \%$ & $\begin{array}{l}\text { Better with } \\
\text { cartilage }\end{array}$ \\
\hline $\begin{array}{l}\text { Demirpehlivan } \\
\text { et al }(2011)^{16}\end{array}$ & 34 & cartilage & Island & $97.7 \%$ & $24.54 \mathrm{db}$ \\
\hline $\begin{array}{l}\text { Demirpehlivan et } \\
\text { al (2011) }\end{array}$ & 67 & Temporalis facia & Underlay & 80.6 & $24.51 \mathrm{db}$ \\
\hline $\begin{array}{l}\text { Demirpehlivan et } \\
\text { al (2011) }\end{array}$ & 19 & cartilage & Palisade & $79.0 \%$ & $23.23 \mathrm{db}$ \\
\hline $\begin{array}{l}\text { Ulkü et al } \\
(2010)^{1}\end{array}$ & 17 & Temporalis facia & - & $88.2 \%$ & $8.5+/-4.4 \mathrm{~dB}$ \\
\hline $\begin{array}{l}\text { Ulkü et al } \\
(2010)^{17}\end{array}$ & 23 & cartilage & & $91.3 \%$ & $9.0+/-3.9 \mathrm{~dB}$ \\
\hline $\begin{array}{l}\text { Lyons et al } \\
(2016)^{18}\end{array}$ & $\begin{array}{l}3,783 \\
\text { unique } \\
\text { studies }\end{array}$ & $\begin{array}{l}\text { temporalis facia } \\
\text { verses cartilage } \\
\text { perichondrium }\end{array}$ & & \multicolumn{2}{|c|}{$\begin{array}{l}\text { no evidence of superiority of one-piece } \\
\text { CCP grafting over TF grafting } 1 \\
\text { tympanoplasty }\end{array}$} \\
\hline \multirow{2}{*}{$\begin{array}{l}\text { Couloigner et al } \\
(2005)^{19}\end{array}$} & 29 & Cartilage & Inlay & \multirow{2}{*}{\multicolumn{2}{|c|}{$71 \%$}} \\
\hline & 29 & Temporalis fascia & Butterfly & & \\
\hline
\end{tabular}

\section{OVERLAY TECHNIQUE}

First technique used for tympanoplasty surgery is overlay technique for placement of graft. In this technique, surface epithelium was removed around the perforation site and graft was put on the fibrous layer of tympanic membrane. This technique is suitable for total perforation of tympanic membrane, anterior perforations and revision cases. Advantages of the technique are graft remains vascularised and middle ear space is not reduced during the procedure. Disadvantages of this procedure are lateralization of graft, blunting of anterior meatal recesses and chances of iatrogenic cholesteatoma formation. Healing may take longer time with use of this technique.

\section{UNDERLAY TECHNIQUE}

Underlay technique was introduced by SHEA. During underlay procedure, the graft was placed medial to the handle of malleus and graft remnant. It is easy to perform. It is an ideal technique to repair tympanic membrane perforations that are easily visualized. Other modifications in the technique of tympanoplasty are done to see the success results. Ralli et al had made anterior and posterior tunnel to create proper tension on the tympanic membrane and handle of malleus. Primrose and Kerr were had made anterior tunnel under the annulus. Sauvage et al had made anterior flap. Farior described elevation of tympanomeatal flap from $12^{\prime} 0$ clock to $3^{\prime} 0$ 
clock position. ${ }^{20}$ This technique is modified by extension of incision from 12'0 clock to $1^{\prime} 0$ clock position to allow the graft to be anchored under the handle of malleus and bony annulus, which allows good graft uptake and postoperative hearing results. The Anterior pull-through is another modified technique where anterior tip of the temporalis fascia was pulled through a short incision lateral to the anterior annulus. Data on graft take rate, pre-operative, and post-operative hearing status were analyzed. Harris et al had showed anatomical success rate of anterior pull-through technique was $84.6 \%$ and the airbone gap reduced to $11.75 \pm 5.7 \mathrm{~dB}$ after surgery. ${ }^{21}$

During underlay technique graft is placed middle to handle of malleus, middle ear space is reduced and there are chances of adhesion formation between promontory and drum. Also gel foam kept during surgery results in adhesion formation. Different comparative studies were done for the results of underlay and overlay techniques by Doyle et al, Glasscock et al and Sergi et al (2011) had done comparative study of overlay and underlay technique in the tympanoplasty showing underlay technique was slightly better than the overlay technique in terms of tympanic membrane closure (94.2\% vs. $91.5 \%)^{22}$

\section{OVERLAY-UNDERLAY TECHNIQUE}

During overlay -underlay technique graft was placed lateral to handle of malleus and medial to tympanic membrane remnant and annulus. This technique is more practically acceptable and is easy to perform. Exposure of middle ear is excellent and ossicles status can be checked. This technique is preferred whenever reconstruction of ossicles is needed. Side effect like anterior blunting is not present with this technique. Various graft material can be used with this technique. Shishegar et al (2012) had used conchal cartilage graft. The perichondrium was removed from one side of the cartilage, and the cartilage was then cut into several slices. Four or five palisades were placed in an over-under fashion in relation to the malleus handle and perichondrium facing laterally. All palisades were supported by the perichondrium to fill the gaps between palisades. $^{13}$

\section{COMBINED TECHNIQUE}

In the combined technique two grafts are placed. One graft was placed under the handle of malleus and tympanic membrane remnants. Second graft is placed on the fibrous layer of tympanic membrane. Gupta et al had $86.6 \%$ success in his overlay technique. ${ }^{23}$ Brown studied Success rate following myringoplasty at the Royal Victoria Eye and Ear Hospital. ${ }^{24}$ Study shows $74 \%$ success in underlay technique and $100 \%$ success in overlay technique. Sengupta et al had done study in 2012 was showing success rates among underlay, overlay and combined technique were $81.25,85.71$ and $90 \%$ respectively. There was no significant difference between acceptance of graft by any technique as per the study done by Vartiainen et al, Frank Rizer et al and Sengupta et al. ${ }^{25-27}$

\section{CIRCUMFERENTIAL SUB ANNULAR GRAFT TECHNIQUE}

In circumferential sub annular graft technique, the graft is put under the annulus, handle of malleus and anteriorly the graft covers the anterior canal wall. Then the reposition of graft remnant is done. In this technique, graft gets anterior support. Graft gets blood supply from the flap. Circumferential sub annular graft technique gives good graft uptake. Study done by Murugendrappa MA et al had shown $96 \%$ success rate. Mokhtarinejad et al reported $95 \%$ success in graft uptake by circumferential sub annular graft technique. ${ }^{28}$ The postoperative mean hearing improvement by circumferential sub annular technique done by Murugendrappa et al had shown hearing improvement by $11 \mathrm{~dB}$ and in the same study by conventional underlay technique, hearing improvement was $8 \mathrm{db}$. Muhammad Rafiq et al and Rahul Kawatra had done conventional underlay technique where graft success rate is $88 \%$ and $87 \%$ respectively which is much lower than study done by Murugendrappa et al. ${ }^{20}$

\section{SWING DOOR TECHNIQUE}

Swinging door tympanoplasty was described by Palva et al in $1969 .{ }^{29}$ It is simple technique and can be used by beginners. In this technique, laterally based skin flap is made. Swinging door flaps are made by cutting tympanomeatal flap, the fibrous annulus and the tympanic membrane. Mokhtarinejad et al reported $95 \%$ success in graft uptake with this technique. There are different studies done to compare results of cartilage and temporalis fascia graft by Shishegar et al, Mohamad et al etc. Most of the studies were showing slightly better results regarding acceptance of graft which were statistically not significant.

\section{BUTTERFLY AND PALISADE TECHNIQUE CARTILAGE TYMPANOPLASTY}

In this technique, cartilage with perichondrium was taken from both sides. Cartilage graft taken is of larger size than the size of perforation. Cartilage is cut in between from periphery and epithelium from edges of the perforation is removed. Edges of the perforation are kept between cartilage perichondrium flaps. Thus the graft is supported from above and below. This technique is commonly used for smaller perforations. Butterfly Cartilage tympanoplasty can be done with the endoscope. Butterfly cartilage tympanoplasty with the use of dermatological punch had shown $92.3 \%$ success in the tympanic membrane closure and air bone gap was improved from 27.67 to 20.1. ${ }^{30}$ Karakullukçu and Eavey had shown high success rate for transcanal butterfly tympanoplasty for non-marginal, small perforations of tympanic membrane perforation closure..$^{31,32}$ 
The palisade technique is preferred in cases of cholesteatoma, ossiculoplasty, atelactasis ear and eustachian tube dysfunction. Perichondrium from one side is removed and the cartilage is sliced. Four or five palisades were placed in an over-under on the malleus handle. Cartilage put in such way that perichondrium faces laterally bridging the gaps between cartilage pieces. Shishegar et al (2012) had used conchal cartilage graft in palisade fashion. ${ }^{13}$ Different modifications are done to use cartilage grafts. Borkowski et al had used U shaped conchal cartilage graft with perichondrium. The size of graft taken is reshapened as size of tympanic ring to seal total perforation of tympanic membrane. ${ }^{33}$ Demirpehlivan (2011) had shown that cartilage island grafts are giving higher success rates than cartilage palisade technique. ${ }^{16}$ There is no difference between functional results of full thickness cartilage and fascia tympanoplasty. ${ }^{8}$

\section{FAT TYMPANOPLASTY}

Fat myringoplasty (FGM) is an office procedure in small perforations. It can be used in all small and medium-large sized perforations. There are various studies done to prove success rate of fat tympanoplasty in dry perforations with intact ossicles. Question of debate is on the size of perforation and acceptance of fat graft.

Gun et al had shown that patients with small perforations had better audiological outcome than medium-large

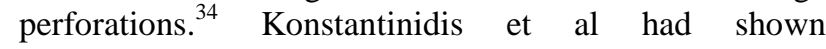
significantly decreased success with perforation size more than $30 \%$ of the pars tensa when fat graft used for tympanic membrane perforation. ${ }^{35}$ Landsberg had done prospective case series study and concluded that Fat graft myringoplasty had long term durability and it is useful in small and medium sized perforations. ${ }^{36}$ Koc et al had shown $90 \%$ success rate irrespective of size of perforation. ${ }^{37}$ Kwong et al had shown $100 \%$ success rate in fat graft tympanoplasty. ${ }^{38}$

\section{HYALURONIC ACID FAT GRAFT}

Hyaluronic acid fat graft technique is nonsurgical technique for myringoplasty. This procedure can be done in clinic without indoor admission. Other office based surgical techniques used are paper patch technique, myringoplasty, fat myringoplasty and topical application of trichloroacetic acid myringoplasty, etc. The reported success rate of closure of the perforation with hyaluronic acid fat graft technique was $81 \%$, with hearing improvement up to $17 \mathrm{db}$. Santa Maria had shown that the success rate is irrespective of site of perforation. ${ }^{39}$ Studies had done to compare different techniques of office based myringoplasties. Also comparision between success of fat and hyuronic acid fat myringoplasty had done by Saliba et al. Saliba et al had shown high success rate of hyaluronic acid fat graft myringoplasty than fat myringoplasty. ${ }^{40}$ Saliba et al had also shown hyaluronic acid fat graft myringoplasty gives equally good results for myringoplasty as that of underlay and overlay technique. ${ }^{41}$ All office-based myringoplasty techniques are equally good. Multiple settings are required for topical application of trichloroacetic acid to achieve complete closure.

\section{CHONDRO-PERICHONDRIAL GRAFT \\ CARTILAGE}

Chondroperichondrial cartilage grafts were used by Dundar et al in 2014 for tympanoplasty. Dundar et al had shown $93 \%$ graft acceptance with air bone gap less than $10 \mathrm{db}{ }^{42}$ Dundar et al had used Boomerang-shaped chondroperichondrial graft in the pediatric chronic otitis media cases with higher grade of graft success rate. ${ }^{43}$

\section{CARTILAGE SHIELD TYMPANOPLASTY}

During the Cartilage shield tympanoplasty perichondrium from both sides of cartilage is removed and notch is made on the cartilage to accommodate malleus. Reshapened cartilage is kept at malleus level through underlay technique and the perichondrium is kept lateral to cartilage graft and medial to tympanic membrane perforation. Advantages of this technique are

- As perichondrium covers posterior canal wall, there is no chance of cholesteatoma and retraction pocket formation.

- It gives better stability to the graft.

- Middle ear space is not reduced.

\section{THE BUTTON GRAFT TECHNIQUE}

Tympanic membrane perforations of small can be sealed with button cartilage graft technique. Button cartilage graft can be used through transcanal route. Abdelghany had used cartilage-perichondrium button graft for tympanic membrane perforations of size less than $25 \%$ of the tympanic membrane and success rate in the tympanoplasty surgery is compared to underlay and overlay technique. The anatomical success rates were $98.5 \%, 97 \%$ and $98.5 \%$ for underlay, overlay and button graft technique respectively. Hearing improvement achieved was $10.18( \pm 5.4) \mathrm{dB}, 8.5(+6.5) \mathrm{dB}$ and 9.1 $(+5.1) \mathrm{dB}$ for underlay, overlay and button graft technique respectively. The mean durations of the operative procedure were $35 \pm 8.4,42 \pm 6.8$, and $23 \pm 6.3$ min for underlay, overlay and button graft technique. Tympanic membrane retraction and cholesteatoma pearls formation were side effects of the underlay and overlay techniques which was not seen in the button graft technique tympanoplasty. ${ }^{44}$

\section{CARTILAGE TYMPANOPLASTY WITH ISLAND TECHNIQUE}

Cartilage tympanoplasty is done in many ways, considering its rigidity question is arising on its resilience and audiological outcome. Ulkü had compared temporalis fascia with cartilage grafts. Anatomic closure rates of the 
tympanic membrane perforation for perichondriumcartilage and fascia group were $91.3 \%$ and $88.2 \%$, respectively. PTA gain of $12.3 \mathrm{~dB}$ for the cartilageperichondrium group and $12.7 \mathrm{~dB}$ for the fascia group. ${ }^{17}$ Demirpehlivan IA had shown cartilage island flap is giving good results. ${ }^{16}$ Dornhoffer had shown that cartilage island flap is used in high risk of reperforation cases. $^{45}$

\section{ENDOSCOPIC VERSES MICROSCOPIC TYMPANOPLASTY}

Comparative studies were done to prove advantage of endoscope and microscope in the success of tympanoplasty. A major limit of endoscopic ear surgery is bleeding. It is difficult to handle bleeding issues in the small space like ear with one hand is with endoscope but in ear surgery like tympanoplasty there are less bleeding issues so endoscopic tympanoplasty technique is still preferred method of tympanoplasty. ${ }^{46}$ With use of endoscope operative time is reduced. ${ }^{39}$ Also it gives better comfort in paediatric patients.

\section{CONCLUSION}

Tympanoplasty is day to day surgery done by ENT surgeons. Site of perforation, size of perforation, ossicular status, audiogram, Eustachian tube dysfunction, status of middle ear mucosa, etc. are the factors make surgeon to decide which technique has to apply to give best anatomical and functional results of surgeries. Among the grafts used for tympanoplasty, cartilage grafts are slightly better to give anatomical and functional outcomes. Temporalis fascia grafts are giving high success rates when used with modified techniques such as circumferential sub annular and anterior pull through techniques. Endoscopic tympanoplasty gives comfort to the patient during surgeries and are time saving, cosmetic, when done under local anaesthesia by endaural approach.

\section{Funding: No funding sources \\ Conflict of interest: None declared \\ Ethical approval: Not required}

\section{REFERENCES}

1. Sarkar S. A review on the history of tympanoplasty. Indian J Otolaryngol Head Neck Surg. 2013;65(3):455-60.

2. Zollner F. The principles of plastic surgery of the sound-conducting apparatus. J Laryngol Otol. 1955;69(10):637-52.

3. Shea JJ. Jr Vein graft closure of eardrum perforations. J Laryngol Otol. 1960;74:358-62.

4. Heermann H. Tympanic membrane plastic with temporal fascia. Hals-Naser-Ohren. 1960;9:136-9.

5. Moore GF. Candidate's thesis: Revision tympanoplasty utilizing fossa triangularis cartilage. Laryngoscope. 2002;112(9):1543-54.
6. Zahnert T, Hottenbrink KB, Morbe $\mathrm{D}$, et al. Experimental in-vestigations of the use of cartilage in tympanic membrane recon-struction. Am J Otol. 2000;21:322-8.

7. Kazikdas KC, Onal K, Boyraz I, Karabulut E. Palisade cartilage tympano-plasty for management of subtotal perforations: a comparison with the temporalis fascia technique. Eur Arch Otorhinolaryngol. 2007;264:985-9.

8. Yegin Y, Çelik M, Koç AK, Küfeciler L, Elbistanlı MS, Kayhan FT. Comparison of temporalis fascia muscle and full-thickness cartilage grafts in type 1 pediatric tympanoplasties. Braz J Otorhinolaryngol. 2016;82(6):695-701.

9. Cavaliere M, Cavaliere M, Mottola G, Rondinelli M, Iemma M. Tragal cartilage in tympanoplasty: anatomic and functional results in 306 cases. Acta Otorhinolaryngol Ital. 2009;29(1):27-32.

10. Marchioni D, Alicandri-Ciufelli M, Molteni G, Genovese E, Presutti L. Endoscopic tympanoplasty in patients with attic retraction pockets. Laryngoscope. 2010;120(9):1847-55.

11. Zhang $\mathrm{T}$, Wang $\mathrm{Z}$, Wu L, Zhang $\mathrm{Y}$, Wang $\mathrm{W}$. Postoperative morbidity of graft tympanic membrane in tympanoplasty and the relevant factors. Lin Chuang $\mathrm{Er} \mathrm{Bi}$ Yan $\mathrm{Hou} \mathrm{Ke} \mathrm{Za}$ Zhi. 2002;16:528-32.

12. Demirci S, Tuzuner A, Karadas H, Acıkgoz C, Caylan R, Samim EE. Comparison of temporal muscle fascia and cartilage grafts in pediatric tympanoplasties. Am J Otolaryngol. 2014;35:296-9.

13. Shishegar M, Faramarzi A, Taraghi A. A Short-term Comparison Between Result of Palisade Cartilage Tympanoplasty and Temporalis Fascia Technique. Iran J Otorhinolaryngol. 2012;24(68):105-12.

14. Mohamad SH, Khan I, Hussain SS. Is cartilage tympanoplasty more effective than fascia tympanoplasty? A systematic review. Otol Neurotol. 2012;33(5):699-705.

15. Onal K, Arslanoglu S, Oncel S, Songu M, Kopar A, Demiray U. Perichondrium/Cartilage island flap and temporalis muscle fascia in type I tympanoplasty. J Otolaryngol Head Neck Surg. 2011;40(4):295-9.

16. Demirpehlivan IA, Onal K, Arslanoglu S, Songu M, Ciger E, Can N. Comparison of different tympanic membrane reconstruction techniques in type I tympanoplasty. Eur Arch Otorhinolaryngol. 2011;268(3):471-4.

17. Ulkü $\mathrm{CH}$. Cartilage tympanoplasty with island technique for reconstruction of tympanic membrane perforation: anatomic and audiologic results. Kulak Burun Bogaz Ihtis Derg. 2010;20(1):7-12.

18. Lyons SA, Su T, Vissers LE, Peters JP, Smit AL, Grolman W. Fascia compared to one-piece composite cartilage-perichondrium grafting for tympanoplasty. Laryngoscope. 2016;126(7):166270.

19. Couloigner V, Baculard F, El Bakkouri W, Viala P, François M, Narcy P, et al. Inlay butterfly cartilage 
tympanoplasty in children. Otol Neurotol. 2005;26:247-51.

20. Murugendrappa MA, Siddappa PN, Shambulingegowda A, Basavaraj GP. Comparative Study of Two Different Myringoplasty Techniques in Mucosal Type of Chronic Otitis Media. J Clin Diagn Res. 2016;10(2):1-3.

21. Harris JP, Wong YT, Yang TH, Miller M. How I do it: Anterior pull-through tympanoplasty for anterior eardrum perforations. Acta Otolaryngol. 2016;136(4):414-9.

22. Sergi B, Galli J, De Corso E, Parrilla C, Paludetti G. Overlay versus underlay myringoplasty: report of outcomes considering closure of perforation and hearing function. Acta Otorhinolaryngol Ital. 2011;31(6):366-7.

23. Gupta SC. Myringoplasty with a single flap. Ear Nose Throat J. 2000;79(12):946-8, 950-1.

24. Brown CYQ, McCarty DJ, Briggs RJS. Success rate following myringoplasty at the Royal Victoria Eye and Ear Hospital. Aust J Otolaryngol. 2002.

25. Vartiainen E, Nuutinen J. Success and pitfalls in myringoplasty: follow-up study of 404 cases. Am J Otol. 1993;14(3):301-5.

26. Franklin M, Rizer MD. Overlay vs underlay technique. Laryngoscope. 1997;107(84):26-36.

27. Sengupta A, Basak B, Ghosh D, Basu D, Adhikari D, Maity K. A study on outcome of underlay, overlay and combined techniques of myringoplasty. Indian J Otolaryngol Head Neck Surg. 2012;64(1):63-6.

28. Mokhtarinejad F, Okhovat SAR, Barzegar F. Surgical hearing results of the circumferential sub annular grafting technique in tympanoplasty randomized clinical study. Am J Otolaryngol Head Neck Surg. 2012;33:75-6.

29. Palva T, PaIva A, Karja J. Myringoplasty. Ann Otol Rhinol Laryngol. 1969;78:1074-80.

30. Belhossine I, Pezzettigotta S, Genty E, Erminy M, Lecanu JB. Modified butterfly cartilage tympanoplasty: retrospective study on 26 patients. Rev Laryngol Otol Rhinol (Bord). 2012;133(2):7780.

31. Karakullukçu B, Acioğlu E, Pamukçu M. Transcanal butterfly cartilage tympanoplasty. Kulak Burun Bogaz Ihtis Derg. 2006;16(4):160-3.

32. Eavey RD. Inlay tympanoplasty: cartilage butterfly technique. Laryngoscope. 1998;108(5):657-61.

33. Borkowski G, Sudhoff H, Luckhaupt H. Autologous perichondrium-cartilage graft in the treatment of total or subtotal perforations of the tympanic membrane Laryngorhinootologie. 1999;78(2):68-72.

34. Gun T, Sozen T, Boztepe OF, Gur OE, Muluk NB, Cingi $\mathrm{C}$. Influence of size and site of perforation on fat graft myringoplasty. Auris Nasus Larynx. 2014;41(6):507-12.
35. Konstantinidis I, Malliari H, Tsakiropoulou E, Constantinidis J. Fat myringoplasty outcome analysis with oto endoscopy: who is the suitable patient? Otol Neurotol. 2013;34(1):95-9.

36. Landsberg R, Fishman G, De Rowe A, Berco E, Berger G. Fat graft myringoplasty: results of a longterm follow-up. J Otolaryngol. 2006;35(1):44-7.

37. Koc S, Akyuz S, Gurbuzler L, Aksakal C. Fat graft myringoplasty with the newly developed surgical technique for chronic tympanic membrane perforation. Eur Arch Otorhinolaryngol. 2013;270(5):1629-33.

38. Kwong KM, Smith MM, Coticchia JM. Fat graft myringoplasty using umbilical fat. Int $\mathbf{J}$ Pediatr Otorhinolaryngol. 2012;76(8):1098-101.

39. Santa Maria PL, Oghalai JS. Is office-based myringoplasty a suitable alternative to surgical tympanoplasty? Laryngoscope. 2014;124(5):1053-4.

40. Saliba I, Knapik M, Froehlich P, Abela A. Advantages of hyaluronic acid fat graft myringoplasty over fat graft myringoplasty. Arch Otolaryngol Head Neck Surg. 2012;138(10):950-5.

41. Saliba I, Froehlich P. Hyaluronic acid fat graft myringoplasty: an office-based technique adapted to children. Arch Otolaryngol Head Neck Surg. 2011;137(12):1203-9.

42. Dündar R, Soy FK, Kulduk E, Muluk NB, Cingi C. A new grafting technique for tympanoplasty: tympanoplasty with a boomerang-shaped chondroperichondrial graft (TwBSCPG). Eur Arch Otorhinolaryngol. 2014;271(10):2687-94.

43. Dundar R, Kulduk E, Soy FK, Aslan M, Yukkaldiran A, Guler OK, et al. Surgical success of boomerang-shaped chondroperichondrial graft in pediatric chronic otitis media cases. Int $\mathbf{J}$ Pediatr Otorhinolaryngol. 2015;79(6):808-11.

44. Abdelghany AM. The button graft technique for perforations affecting less than $25 \%$ of the tympanic membrane: a non-randomised comparison of a new modification to cartilage tympanoplasty with underlay and overlay grafts. Clin Otolaryngol. 2013;38(3):208-16.

45. Dornhoffer J. Cartilage tympanoplasty: indications, techniques, and outcomes in a 1,000-patient series. Laryngoscope. 2003;113(11):1844-56.

46. Nassif N. Response to the Letter to the Editor regarding "Tympanic membrane perforation in children: Endoscopic type I tympanoplasty, a newly technique, is it worthwhile?" by Nassif et al. Int J Pediatr Otorhinolaryngol. 2016;80:110-1.

Cite this article as: Chavan RP, Ingole SM, Birajdar SN. Overview of tympanoplasty techniques and results. Int J Otorhinolaryngol Head Neck Surg 2017;3:170-5. 